\title{
ALVES JUNIOR, E. D. (Org.) Envelhecimento e vida saudável 2. Rio de Janeiro: Apicuri, 2010.
}

\author{
Cristina Borges de Oliveira
}

Universidade Federal Fluminense, Niterói, Rio de Janeiro, Brasil

Este texto objetiva resenhar o livro Envelhecimento e vida saudável 2, organizado pelo professor doutor Edmundo de Drummond Alves Junior, da Universidade Federal Fluminense, no Rio de Janeiro (RJ). Trata-se de um conjunto de reflexões que busca enriquecer os diálogos acadêmicos que possuem como proposta epistemológica investigações e discussões que tematizam o envelhecimento a partir de uma perspectiva multidisciplinar. A literatura em questão foi construída ancorada nos interesses do grupo de pesquisa Envelhecimento e Atividade Física (GPEAF) do Instituto de Educação Física da Universidade Federal Fluminense.

Salienta-se nesta resenha a relevância social e científica das narrativas que são resultados de pesquisas que versam sobre corporeidade, práticas corporais, envelhecimento e saúde. Destaca-se também a importância das narrativas sobre o aumento da expectativa de vida dos sujeitos associada a diferentes propostas de exercícios físicos, além das possibilidades de prevenção e reabilitação de doenças, tais como: neurovegetativas, coronárias, hipertensão, diabetes, entre outras.

$\mathrm{O}$ conjunto da obra traz à baila os benefícios da atividade física tomada como hábito, associada à diminuição de um considerável índice de doenças, no cômputo geral, levantando a possibilidade de ampliação da longevidade. Os estudos apresentados têm como referência tanto o viés das Ciências da Saúde quanto os paradigmas das Ciências Sociais e Humanas.

A compilação de textos é resultado de uma empreitada coletiva, surgindo como mais uma possibilidade de resposta aos apelos por indicações de caminhos para uma compreensão ampliada sobre o que 
seja o processo de envelhecimento e vida saudável. As reflexões apresentadas estão dispostas em onze artigos em forma de textos independentes que se inter-relacionam para dar conta de uma discussão ampliada e multidisciplinar da temática proposta, destacando questões polêmicas e carentes de debates no âmbito acadêmico.

O livro apresenta uma grande diversidade de profissionais como autores, o que o enriquece com múltiplos olhares sobre o tema proposto, estimulando outras pesquisas através de uma visão multifacetada sobre a relação entre o processo do envelhecimento e a cultura corporal. As ideias apresentadas tornam sua leitura muito interessante para profissionais de distintas áreas acadêmicas, como: Educação Física, Educação, Fisioterapia, Enfermagem, Geriatria, Gerontologia, Gestão Educacional, Medicina, Serviço Social, Terapia Ocupacional, entre outras.

Vale destacar que os diferentes estudos apresentados podem ser tomados como referência teórica por aqueles que elaboram/projetam/propõem políticas públicas, sejam elas de saúde (prevenção e tratamento), de educação, de cultura, de lazer e de esportes. Os estudos em questão também são relevantes para aqueles profissionais em formação (inicial ou continuada) que se interessam pela temática cultura corporal - envelhecimento -, saúde e qualidade de vida.

A obra organizada apresenta investigações atuais e aponta o interesse acadêmico crescente por experiências e resultados de pesquisas científicas que têm como objeto de investigação os adultos mais velhos e os processos de envelhecimento humano. Advoga um (re)pensar do conceito historicamente recorrente que caracteriza a velhice terceira idade ${ }^{1}$-apenas levando em conta a idade cronológica. Essa generalização, segundo os autores dos textos que compõem o livro, rotula os sujeitos em tela a partir de uma perspectiva que toma como principal referência apenas aqueles adultos mais velhos que possuem boa forma física não acometida por mobilidade reduzida, que não têm comprometimento intelectual e que gozam de relativa autonomia pessoal e estabilidade econômica. Sujeitos inseridos socialmente, ativos afetiva e sexualmente. Os artigos propõem aos leitores um olhar que amplia o conceito de envelhecimento, a noção de qualidade de vida e a promoção de saúde.

1-Termo bastante difundido nas produções científicas e mesmo em veículos de informação/comunicação de massa.

Pensar a Prática, Goiânia, v. 15, n. 2, p. 272-550, abr./jun. 2012

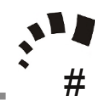


É um recorte que compreende que o engajamento regular dos adultos mais velhos em práticas corporais e socioculturais pode contribuir para a manutenção da autonomia dos indivíduos em face do processo paulatino de perda desse estado autônomo inerente a todo ser vivente. A explicação para essa perda de autonomia se sustenta, historicamente, em inúmeros e complexos fatores contributivos, como a expropriação do sujeito trabalhador, associada à política de baixos salários para os aposentados, e a dificuldade encontrada por adultos mais velhos de recolocação no mercado de trabalho. Destaca-se, ainda, o não atendimento dos direitos constitucionais primários - saúde, moradia digna, saneamento básico, gratuidade no transporte, segurança, educação, políticas de cultura, políticas de esporte e lazer - e a falta de respeito ao Estatuto do Idoso.

No âmbito geral, os estudos presentes no livro observam, registram e definem conceitualmente quais dificuldades - por exemplo, a financeira - estão entre os eventos mais recorrentes que contribuem para a perda de autonomia, associados aos componentes físicos do ambiente e à incidência de algumas doenças crônicas, incluindo as ocupacionais. De acordo com a obra em questão, as limitações de ordem física e/ou mental causadas por fatores diversos somam-se aos fatores influenciadores na perda de autonomia do indivíduo adulto mais velho. Contudo, a necessidade do uso de equipamentos auxiliares na marcha para prevenir quedas e a importância da acessibilidade para o exercício da cidadania ainda são temas carentes de investigação.

Os elementos gerados pelas pesquisas apresentadas no livro podem contribuir, significativamente, para que os gestores e analistas de políticas, organizações não governamentais, associações civis, entre outras, tomem decisões efetivas na formulação de propostas que humanizem o processo de construção de políticas públicas que atendam o envelhecer de forma saudável. O livro em foco discute aspectos atuais como: alterações neuromusculares relacionadas ao processo de envelhecimento, medo de quedas, além de uso de equipamentos auxiliares na marcha e prática do tai-chi-chuan como alternativas para a prevenção de quedas de sujeitos adultos mais velhos.

As discussões em tela trazem à tona questões que sublinham a indissociabilidade entre ensino, pesquisa e extensão. Destacam o tema envelhecimento e suas imbricações com a formação em saúde na Universidade Federal Fluminense, bem como com a disciplina Trabalho de Campo Supervisionado (TCS-I). Sublinham aspectos fisiológicos 
do exercício no envelhecimento, treinamento, força muscular e aumento de massa em idosos, além de refletir sobre a importância das relações e interações sociais na constituição de uma vida saudável e na reabilitação/recuperação e superação do medo das quedas. As preocupações com a formação continuada de agentes sociais e o envolvimento comunitário também são contemplados nessa leitura e são apresentados como possíveis interfaces das temáticas que permeiam o envelhecimento.

No livro há uma compilação de alguns importantes aspectos que caracterizam as práticas corporais para o público em cena. São sublinhados, além de outros aspectos, alguns fatores que podem influir direta ou indiretamente no aumento de massa muscular do adulto mais velho, no desempenho no treinamento de força muscular individual, na prevenção de quedas e na reabilitação de movimentos, o que pode contribuir com as expectativas de vida saudável.

A partir de uma abordagem multifacetada da temática em cena, a obra levanta a importância do redimensionamento do papel do educador a partir da discussão sobre as práticas corporais na educação de adultos mais velhos e o desafio da intergeracionalidade no tocante às reflexões sobre Educação Física escolar.

Pode-se concluir que o livro em questão foi construído à luz de alguns olhares que se complementam, quais sejam: o olhar das instituições de educação superior onde são desenvolvidas investigações sobre os temas em foco, onde são oferecidas ações de extensão que muitas vezes se constituem locus de pesquisa, onde se concentram os responsáveis pela formação dos profissionais que atuam com os sujeitos em tela; o olhar daqueles que necessitam de se adaptar à nova realidade (o envelhecimento corporal), buscando condições efetivas de saúde, lazer e atividades corporais; e, por último, mas não menos importante, o olhar dos agentes de promoção de educação e saúde, profissionais que são desafiados a atuar no mundo extraescolar.

A obra, em seu conjunto, é interessante e recomendável pela atualidade dos temas e também por sua relevância social e científica. Enfatiza-se aqui que tal conjunto de reflexões pode contribuir para aqueles que desejam se aproximar dessa área em ascensão. As informações apresentadas no corpo dos textos transformam a leitura instigante, oferecendo a oportunidade de reconhecimento da necessidade desses conhecimentos para a reorganização de noções, conceitos sobre o 
processo de envelhecimento e estratégias de ações para a construção de uma referência de vida saudável na contemporaneidade.

\section{Referências}

ALVES JUNIOR, E. D. (Org.). Envelhecimento e vida saudável 2. Rio de Janeiro: Apicuri, 2010. 248 p.

Recebido em: 20/08/2011

Revisado em: 15/11/2011

Aprovado em: 27/01/2012

\section{Endereço para correspondência}

cristinaborges@id.uff.br

Cristina Borges de Oliveira

Universidade Federal Fluminense

Departamento de Educação Física e Desportos

Rua Visconde do Rio Branco, $\mathrm{s} / \mathrm{n}^{\circ}$ - Centro

Niterói - RJ - CEP 24020-006

Brasil 